\title{
A RELAÇÃO PÚBLICO-PRIVADO NA EDUCAÇÃO INFANTIL E A NOVA GESTÃO PÚBLICA
}

\author{
THE PUBLIC-PRIVATE RELATIONSHIP IN PRESCHOOL EDUCATION \\ AND THE NEW PUBLIC MANAGEMENT
}

\author{
Rosânia Campos \\ Doutora em Educação, Universidade da Região de Joinville \\ UNIVILLE, Joinville/SC, Brasil \\ zana.c2001@gmail.com \\ Janaína Silveira Soares Madeira \\ Mestre em Educação, Universidade da Região de Joinville \\ UNIVILLE, Joinville/SC, Brasil \\ janaina.madeira@univille.br
}

Resumo: Este trabalho é parte integrante de uma pesquisa que teve como objetivo investigar a relação entre o público e o privado na oferta de vagas na Educação Infantil na maior cidade do Estado de Santa Catarina. Para esse trabalho, optamos por discutir, de modo mais específico, a ampliação da estratégia de conveniamento e a repercussão desta ampliação no contexto das políticas públicas. É uma pesquisa qualitativa, composta por revisão bibliográfica e por um trabalho de campo realizado via questionários junto a todas as instituições conveniadas e entrevistas semiestruturadas com técnicas da Secretaria Municipal de Educação, a partir dos quais os dados foram construídos. As análises indicam que, embora não seja uma estratégia nova, o conveniamento, após a aprovação da Lei 12.796/2013, que determina a obrigatoriedade da matrícula aos quatro anos, foi ampliado, incluindo as instituições privadas com fins lucrativos, indicando uma "nova gestão pública" (DALE, 2014).

Palavras-chave: Políticas para educação infantil. Relação público-privado. Conveniamento na educação infantil.

Abstract: This paper is part of a research, which aimed to investigate the relationship between public and private in the offer of vacancies in Preschool Education, in the largest city of Santa Catarina State. For this paper we have chosen to discuss, specifically, the expansion of the convenience strategy and the impact of this expansion in the context of public policy. It is a qualitative research, comprising literature review and field work performed via questionnaires with all partner institutions and semistructured interviews with Municipal Education techniques, from which the data was built. The analysis indicates that, although it is not a new strategy, the public-private agreement, after the approval of the law 12.796/2013 that defines the compulsory enrollment by the age of four, was extended to private institutions including being for-profit, indicating a "new public management" (DALE, 2014).

Keywords: Policies for child education. Public-private relationship. Convenience in preschool education.

\section{Para citar - (ABNT NBR 6023:2018)}

CAMPOS, Rosânia; MADEIRA, Janaína Silveira Soares. A relação público-privado na educação infantil e a nova gestão pública. Eccos - Revista Cientifica, São Paulo, n. 55, p. 1-15, e8852, out./dez. 2020. Disponível em: https://doi.org/10.5585/eccos.n55.8852. 


\section{Educação infantil no Brasil}

A Educação Infantil no Brasil foi tardiamente reconhecida como direito subjetivo, precisamente, em termos legais, somente após a Constituição de 1988. Importante lembrar que o período de promulgação da Constituição tanto é marcado pelo processo de abertura política, quanto pelo processo de ajustes fiscais e de redefinição do papel do Estado, em curso, de modo especial, na Inglaterra e nos Estados Unidos, a partir da lógica neoliberal. Assim, se por um lado, como afirma Vieira (2001), em nenhum outro momento a política social nacional encontrou maior acolhimento do que na Constituição de 1988; por outro, o país também sofria os impactos das estratégias do capital para a superação de sua crise, com as políticas neoliberais, a reestrutura produtiva e o processo de globalização, já em curso em outros países, sendo iniciado no Brasil (PERONI, 2011).

Nesse contexto, é possível observar um descompasso entre a abertura política, a luta pelos direitos sociais e políticos e as indicações advindas do processo de reestruturação produtiva, resultando, em 1995, na definição da urgência de reforma do Estado, de modo que, sob a responsabilidade de Bresser-Pereira, foi definido um Plano Diretor da Reforma do Aparelho do Estado - PDRAE, pois o Estado era considerado o grande vilão promotor da crise. Foram definidas novas indicações para o papel do Estado na proposição, na definição e na execução, sobretudo, das políticas sociais.

Essas modificações impactaram duramente, em especial, a Educação Infantil. É necessário lembrar que essa etapa educativa não foi originada como uma política social de Estado, "antes sua trajetória inicial foi marcada como uma ação para assistir às famílias trabalhadoras, desse modo, não foi criada no sentido de uma política social universal, mas como uma ação focal do Estado" (CAMPOS, 2017). Dessa forma, é possível compreender que a Educação Infantil foi muito mais concebida como uma ação assistencialista associada ao processo civilizatório, gestada a partir da lógica das necessidades individuais e não coletivas. Em outras palavras, foi concebida sob a égide de uma ação dirigida para necessidades individuais de determinadas famílias, desconsiderando a questão do direito social de todas as demais (CAMPOS, 2008).

Nessa conjuntura, foi aprovada a Lei de Diretrizes e Bases da Educação Nacional - LDB (Lei $n^{\circ}$ 9.394/1996), na qual a Educação Infantil foi reconhecida pela primeira vez como compondo a Educação Básica. Esta conquista também foi marcada pelas disputas em curso. Dessarte, é possível observar que o atendimento em creche, definido no art. 30 da citada Lei, prevê que a Educação Infantil será ofertada em creches ou entidades equivalentes, para crianças 
de até três anos de idade, o que evidencia as negociações e disputas que marcaram esse processo. Isto é, o texto da LDB foi definido na tensão entre movimentos sociais que ainda lutavam pela consolidação da democracia e de um Estado de direitos; e executivo, com forte adesão ao projeto neoliberal que, na época, incitava uma minimização da participação do Estado, mormente, no provimento de políticas sociais.

Mister lembrar que, nessa década, foi realizado o Fórum Mundial de Educação em Dakar (2001), sob o auspícios da Unesco, que indicava a centralidade do Ensino Fundamental, onde os países signatários deveriam atender às metas estabelecidas no encontro. No Brasil, a repercussão nas políticas educacionais das indicações realizadas no Fórum foram visíveis. Assim, por exemplo, houve a proposição de um fundo para garantir subvinculação dos recursos da educação para o Ensino Fundamental, excluído desse a Educação Infantil e o Ensino Médio ${ }^{1}$.

Em síntese, é nesse cenário que observamos o crescimento de estudos e pesquisas que versam sobre Educação Infantil e a expansão de matrículas. Também nesse período, testemunhamos as modificações na Educação Básica que repercutiram diretamente na Educação Infantil, como a Lei de matrícula aos seis anos no Ensino Fundamental (Lei no 11.114/2005), a Lei do Ensino Fundamental de nove anos (Lei $\left.n^{\circ} 11.274 / 2006\right)$ e, mais recentemente, a Lei de obrigatoriedade de matrícula aos quatro anos (Lei n 12.796/2013). Não obstante, todas essas alterações não resultaram diretamente na ampliação de vagas na Educação Infantil. Ainda seguem as discussões que se referem a orientações pedagógicas (recentemente essas discussões ganharam novos contornos com a divulgação da terceira versão da Base Nacional Curricular Comum) e a avaliação de qualidade nessa etapa educativa.

Tendo em consideração todos esses aspectos, o presente trabalho tem por objetivo discutir como a maior cidade do Estado de Santa Catarina tem ofertado Educação Infantil, principalmente após a obrigatoriedade de matrícula aos quatro anos. Organizamos o texto em quatro sessões: na primeira, procuramos discutir a ampliação de vagas na Educação Infantil por meio da estratégia de conveniamento; em seguida, apresentamos como o presente estudo foi desenvolvido; na sequência, o cenário da investigação analisando os dados locais; na quarta sessão, realizamos algumas reflexões no sentido de subsidiar o debate e dialogar com pesquisadores da área.

\footnotetext{
${ }^{1}$ Essa situação é modificada anos depois, especialmente pelas pressões populares e gestores municipais, bem como pelas novas orientações advindas do Fórum Mundial de Educação para Todos (DAKAR, 2001). Para maiores discussões sobre esse fato indicamos "AUTOR", 2008. 


\title{
Relação público-privado na educação infantil: o que mudou?
}

De acordo com Kramer (2001), o Estado brasileiro jamais assumiu integralmente a responsabilidade pela Educação Infantil, sendo prática histórica a divisão dessa tarefa com a iniciativa privada, quer seja por meio de associações filantrópicas ou por instituições sem fins lucrativos. Desse modo, a relação público-privado na Educação Infantil não é um fenômeno novo, estando alicerçada, principalmente, nos municípios com densidade populacional mais elevada, havendo, ainda, a prática da compra de vagas pelo poder público municipal em escolas privadas, para atender crianças cujas famílias não encontram vagas em escolas públicas (SUSIN e MONTANO, 2015, p. 76).

Além dessa marca histórica, outra também é observada, a da persistência em se fomentar políticas de baixo custo para atender a Educação Infantil. Por isso a expansão da Educação Infantil ocorreu numa sinergia perversa entre espaço inadequado, precariedade de material pedagógico e ausência de qualificação profissional das educadoras, resultando em ambientes educacionais pouco favoráveis ao enriquecimento das experiências infantis (ROSEMBERG, 2002, p. 35). Seguindo essa perspectiva, Kuhlmann Jr., (2015, p. 184) destaca que:

\begin{abstract}
$\mathrm{O}$ atendimento educacional da criança pequena passa a ser visto como um favor aos pobres, que se estabelece por meio do repasse das escassas verbas públicas às entidades assistenciais, legitimando-as como intermediárias na prestação do serviço à população. A baixa qualidade se transforma em algo aceito como natural, corriqueiro e mesmo necessário. Com isso, abrem-se as portas para os usos político e religioso da instituição: a creche funciona com dinheiro público, mas a entidade, por oferecer o serviço, age como se tivesse o direito de utilizar o equipamento para se autopromover, para dar prestígio a políticos, para doutrinação teológica e confessional, numa afronta às liberdades fundamentais do cidadão, definidas por nossa Constituição.
\end{abstract}

Esse modo de fazer política para Educação Infantil, apesar das pesquisas indicarem seus problemas, suas limitações e suas injustiças, é reforçado a partir da década de 1990, conforme indicamos anteriormente, quando ocorreu a Reforma do Estado (Plano Diretor de Reforma do Aparelho do Estado - PDRAE, 1995), a partir do qual houve o rompimento da exclusividade do Estado sobre a oferta do ensino público, com incentivo às parcerias público-privado (ADRIÃO e PERONI 2011).

Entretanto, conforme destaca Dale (2014), é necessário considerar que a distinção entre público e privado não consegue captar as modificações geradas nos sistemas educativos a partir dessa relação. Ainda segundo o autor, é fundamental compreender que esse processo não ocorre como se fosse um deslocamento linear do público para o privado, isto é, como uma simples transferência das responsabilidades públicas para a esfera privada. Essa relação implica em um 
conjunto muito mais complexo de mudanças nos mecanismos institucionais, que implicam novas regulações ou modos de regulação nas instituições. Nesse sentido, é uma ideia equivocada compreender que essa ampliação de parceria entre público-privado resulta em uma diminuição no papel do Estado. Pelo contrário, o que é possível observar são novas formas e combinações de financiamento, rediscussão do papel da sociedade civil e, como já dito, a própria regulação da educação.

No caso específico da Educação Infantil, em que pese a tradição de transferir para a própria população a responsabilidade pela oferta dessa etapa (Lei $\left.n^{\circ} 11.494 / 2007\right)$, com a aprovação da Lei da obrigatoriedade da matrícula aos quatro anos (Lei n ${ }^{\circ}$ 11.274/2006), observamos um incremento nessa relação, como constatamos em pesquisas anteriores (CAMPOS, 2015). Nessa lógica, o incremento de instituições conveniadas, o que significa também um aumento de instituições e organizações não governamentais, configura, similarmente, uma nova função para essas instituições.

Dito de outro modo, consoante preceituado por Fontes (2006), as instituições se afastam de sua prerrogativa inicial, de ser um modo de organização e pressão social, e passam a ser organizadas sob nova lógica, a qual contribuiu para "uma diluição importante do significado do engajamento social e para embaralhar a percepção da real dimensão da luta que se travava" (FONTES, 2006, p. 234). Nesse processo, a sociedade civil é definida como a grande responsável pela consolidação de direitos e da democracia, correndo-se o risco de obscurecer, conforme indica Fontes (2006) a própria composição de classes sociais existentes no interior dessa sociedade.

Essas modificações, sob nosso ponto de vista, a partir do qual o governo age em parceria com instituições da sociedade civil, são um indicativo da construção de uma política da Terceira Via. De acordo com Giddens (2005), não são fronteiras permanentes entre governo e sociedade civil, de modo que, dependendo do contexto, o governo deve ser "empurrado" para a arena civil, em outros momentos deve recuar. E continua o autor:

Onde o governo se abstém de envolvimento direito, seus recursos podem continuar
sendo necessários para apoiar atividades que grupos locais desenvolvem ou
introduzem - sobretudo em áreas mais pobres. Contudo, é particularmente em
comunidades mais pobres que o incentivo à iniciativa e ao envolvimento locais podem
gerar o maior retorno (GIDDENS, 2005, p. 90, grifo nosso).

Contudo, ainda segundo Giddens (2005), essas parcerias não excluem o Estado, mas exigirão novos modos de regulação realizados por este, o que para nós indica o que Dale (2014) definiu como uma "nova gestão pública", isto é, a reformulação do Estado em uma forma mais 
parecida com o mercado, semelhante ao mundo dos negócios. Seguindo essa lógica, “o Estado precisa tanto extrair sustento da sociedade civil como desempenhar papel ativo em regulá-la" (GIDDENS, 2007, p. 25).

Para além desses aspectos, o que a presente pesquisa indicou foi o conveniamento, na Educação Infantil, com instituições educativas com fins lucrativos, o que nos parece pertinente ao considerarmos as discussões anteriores sobre as indicações da urgência em se rever a função do Estado. Desta maneira, a transferência de recursos públicos para instituições privadas com fins lucrativos não é problematizada, tendo em vista que, como bem defende a política da Terceira Via, "o empreendedorismo civil é uma qualidade de uma sociedade civil modernizada. Ele é necessário para que os grupos cívicos produzam estratégias criativas e enérgicas para ajudar na lida com problemas sociais" (GIDDENS, 2007, p. 27).

A seguir buscamos apresentar como o presente estudo foi desenvolvido, ao mesmo tempo em que procuramos contextualizá-lo.

\section{Caminhos do estudo}

Após submissão e aprovação de projeto no Comitê de Ética em Pesquisa, obedecendo aos procedimentos éticos estabelecidos para a pesquisa científica em ciências humanas, a presente pesquisa foi desenvolvida junto a 40 (quarenta), das 49 (quarenta e nove) instituições indicadas pela Secretaria de Educação do Município que possuíam convênio ${ }^{2}$ com a secretaria municipal de educação da cidade em estudo, no ano de 2017, oferecendo vagas públicas conveniadas na Educação Infantil.

Para construção dos dados foram utilizadas duas estratégias: a) entrevistas com técnicas da Secretaria Municipal de Educação, tanto do setor pedagógico, quanto do setor responsável pelos convênios; e b) questionário, entregue em mãos, nas 49 (quarenta e nove) instituições conveniadas.

Inicialmente, foi realizado contato telefônico com cada um dos responsáveis pelos 49 (quarenta e nove) Centros de Educação Infantil - CEIs indicados e que firmaram convênio no ano da pesquisa, convidando-os a participar e combinando a entrega do questionário. Esse

\footnotetext{
2 O processo de conveniamento é realizado via edital público no qual são estabelecidos critérios que as instituições interessadas precisam atender. Após as inscrições no edital e comprovação documental, uma equipe da Secretaria Municipal de Educação define as instituições conveniadas e o número de vagas que poderão assumir. Por questões de limitação de número de páginas, e por não ser o objetivo central desse artigo, não é possível apresentar todos os critérios exigidos, no entanto, cabe destacar que os critérios se referem principalmente às instalações físicas e exigências da vigilância sanitária, com os critérios referentes aos aspectos pedagógicos se resumindo praticamente à exigência de ter uma pedagoga com formação.
} 
instrumento foi elaborado com questões fechadas e abertas e entregue pessoalmente em cada instituição, juntamente com o Termo de Consentimento Livre e Esclarecido, em envelopes lacrados e dirigidos aos responsáveis contatados via telefone.

A opção de entregar o questionário em mãos, após contato telefônico pelo qual foi agendado horário e dia da entrega, teve como premissa a ideia de explicar a pesquisa, seu objetivo e, ao mesmo tempo, firmar o compromisso de devolução das análises ao término da investigação. Esse processo, apesar de moroso e com significativo grau de dificuldade, foi muito profícuo, sobretudo porque oportunizou as pesquisadoras conhecerem as instituições, tanto no sentido geográfico quanto das suas instalações físicas. Soma-se a esse o fato de que a conversa inicial resultou em um número considerável de devolução respondida dos questionários, pois das 49 (quarenta e nove) instituições conveniadas, 40 (quarenta) devolveram o questionário respondido.

Sendo assim, dos 49 (quarenta e nove) questionários entregues nas instituições, obtevese o retorno de 44 (quarenta e quatro) questionários, dentre esses 03 (três) devolvidos em branco e 01 (um) questionário foi excluído da análise de dados, perfazendo 40 (quarenta) questionários devolvidos respondidos. Um questionário foi excluído porque, apesar da instituição constar na lista entregue pela Secretaria de Educação de instituições conveniadas, ela não firmou convênio em 2017, ano da investigação, representando, dessa forma, 81,63\% de respondentes.

Após a coleta dos questionários, teve início o processo de tabulação, resultando em diversas tabelas que oportunizaram visualizar muitos aspectos desse processo. De modo similar, as entrevistas foram transcritas e posteriormente analisadas. As entrevistas foram realizadas com técnicas da Secretaria de Educação, responsáveis pelo setor de convênios e fiscalização, organizada de forma semiestruturada, com aberturas conforme a fala das entrevistadas.

O referencial teórico utilizado para análise foi, de maneira predominante, os autores que apresentam uma perspectiva crítica do Estado e de sua função, onde procuramos investigar as modificações do Estado por meio das discussões e análises de Roger Dale.

Para auxiliar nas discussões e reflexões, optamos por analisar as entrevistas por meio de uma aproximação da proposta de análise de discurso desenvolvida por Fairclough (2001), considerando os textos a partir de uma perspectiva tridimensional, iniciando pela dimensão da prática discursiva e pela intertextualidade. Tendo em vista o objetivo desse texto e o limite de páginas indicado, iremos discutir de forma pontual o processo de expansão do conveniamento no município. 


\section{Educação infantil na "Manchester catarinense"}

A maior cidade de Santa Catarina possui 554.601 mil habitantes, segundo estimativa do IBGE (2010), sendo a cidade mais populosa do Estado, apresentando Índice de Desenvolvimento Humano - IDHM de 0,809, considerado muito alto. Mas, ao analisarmos os indicadores que compõe o IDHM, notamos que a educação é o que apresenta o menor índice $(0,749)$, denotando que, apesar do IDHM alto, essa área é um desafio para o município. No que se refere a sua economia, apesar de ser o terceiro polo industrial da região sul, o terceiro PIB do sul do país, seu índice de Gini é de 0,49, indicando distribuição muito desigual de renda, apesar de ser um pouco acima do índice do Estado.

Em relação à Educação Infantil, o município atinge $43 \%$ de suas crianças (PNUD/IPEA/FUNDAÇÃO JOÃO PINHEIRO, 2013), índice bem abaixo do atendimento do segundo e terceiro maiores municípios do Estado. Quando observamos o atendimento por etapa educacional, o município segue a tendência histórica, qual seja, maior atendimento na préescola. Assim, em 2017 havia 6.292 matrículas na creche e 10.470 matrículas na pré-escola. Destas, quando analisamos o período de atendimento, temos 3.104 matrículas em creche, em regime de atendimento parcial, e 3.188 matrículas em creche, em atendimento integral; como é possível observar, praticamente há uma divisão das vagas entre as duas formas de atendimento. Situação muito diferente é observada na pré-escola, onde 10.457 matrículas correspondem ao atendimento parcial, e apenas 13 matrículas são em regime integral.

Quando analisamos esses dados em sentido retrospectivo, a partir do ano da aprovação da Lei da obrigatoriedade da matrícula aos quatro anos, observamos que houve uma ampliação de vagas, conforme é possível demonstrar no quadro abaixo:

Quadro 1 - Evolução das matrículas na educação infantil

$\begin{array}{lccccc}\text { Município } & \mathbf{2 0 1 3} & \mathbf{2 0 1 4} & \mathbf{2 0 1 5} & \mathbf{2 0 1 6} & \mathbf{2 0 1 7} \\ \text { Joinville } & 11.170 & 11.513 & 12.822 & 14.567 & 16.762\end{array}$

Fonte: Elaboração própria a partir do INEP, 2018.

No entanto, necessário destacar que essa ampliação de vagas resultou de duas estratégias privilegiadas: a parcialização do atendimento e a ampliação de conveniamento. Em relação ao período de atendimento, no mesmo intervalo, temos a seguinte situação: 
Quadro 2 - Evolução de matrículas por período de atendimento

\begin{tabular}{llllllllllll} 
Município & 2013 & & 2014 & & 2015 & & $\mathbf{2 0 1 6}$ & \multicolumn{2}{c}{2017} & \\
Período & I. & P. & I. & P. & I. & P. & I. & P. & I. & P. \\
Joinville & 5.227 & 5.579 & 5.374 & 5.848 & 3.734 & 6.820 & 5.113 & 7.438 & 3.428 & 11.493
\end{tabular}

Fonte: Elaboração própria a partir do FNDE, 2017.

Conforme é possível observar, a ampliação das matrículas não significou expressivo aumento de vagas, tendo em vista que essa ampliação representou diminuição do número de vagas em período integral. Dessa forma, ao considerarmos os números absolutos no período indicado, temos que 5.227 matrículas em período integral em 2013 foram reduzidas para 3.428 matrículas em 2017, o que significa 1.799 matrículas a menos. Em relação ao atendimento parcial, o processo foi inverso: em 2013, havia 5.579 matrículas em regime parcial, e em 2017, esse número foi para 11.493, indicando um aumento de 3.780 matrículas. Portanto, se considerarmos que foram diminuídas 3.428 matrículas em regime integral, e no mesmo período houve o incremento de 3.780 matrículas em regime parcial, há uma variação de 352 matrículas, que poderiam significar efetivamente novas vagas. Dito de outro modo, se considerarmos que uma matrícula em período integral deveria corresponder a duas matrículas em regime parcial, deveríamos ter tido um incremento de 6.856 no período parcial, o que não ocorreu.

Esse cenário se torna ainda mais complexo quando desdobramos os números considerando as instituições públicas e as instituições conveniadas. Na mesma variação de período, temos a seguinte situação:

Quadro 3 - Evolução de matrículas considerando o tipo de instituição

$\begin{array}{lllll}\text { Ano } & \text { Creche conveniada } & \text { Creche pública } & \text { Pré-escola conveniada } & \text { Pré-escola pública } \\ \mathbf{2 0 1 3} & 863 & 4.773 & 965 & 6.033 \\ \mathbf{2 0 1 4} & 912 & 4.921 & 1.075 & 6.301 \\ \mathbf{2 0 1 5} & 907 & 4.876 & 1.040 & 6.678 \\ \mathbf{2 0 1 6} & 840 & 5.588 & 1.176 & 6.963 \\ \mathbf{2 0 1 7} & 1.275 & 5.581 & 1.017 & 9.340\end{array}$

Fonte: Elaboração própria a partir do FNDE, 2017.

Esses números indicam que a opção por conveniamento foi mais fortemente realizada na etapa creche, indicando que para a pré-escola o incremento via essa estratégia foi menor. E, 
quando desdobramos esses dados considerando o período de atendimento, temos o seguinte panorama:

Quadro 4 - Evolução de matrículas considerando o tipo de instituição e o tempo e atendimento

\begin{tabular}{|c|c|c|c|c|c|c|c|c|}
\hline \multirow{2}{*}{ Ano } & \multicolumn{2}{|c|}{$\begin{array}{c}\text { Creche } \\
\text { conveniada }\end{array}$} & \multicolumn{2}{|c|}{ Creche pública } & \multicolumn{2}{c|}{ Pré-escola pública } & \multicolumn{2}{c|}{$\begin{array}{c}\text { Pré-escola } \\
\text { conveniada }\end{array}$} \\
\cline { 2 - 9 } & Integral & Parcial & Integral & Parcial & Parcial & Parcial & Integral & Parcial \\
\hline $\mathbf{2 0 1 3}$ & 497 & 366 & 3679 & 1094 & 1548 & 4485 & 486 & 479 \\
\hline $\mathbf{2 0 1 4}$ & 429 & 483 & 3760 & 1161 & 1614 & 4687 & 426 & 649 \\
\hline $\mathbf{2 0 1 5}$ & 503 & 404 & 3620 & 1256 & 1114 & 5564 & 400 & 640 \\
\hline $\mathbf{2 0 1 6}$ & 417 & 423 & 4146 & 1442 & 967 & 5996 & 421 & 755 \\
\hline $\mathbf{2 0 1 7}$ & 756 & 519 & 3415 & 2166 & 13 & 9327 & 152 & 865 \\
\hline
\end{tabular}

Fonte: Elaboração própria a partir do FNDE, 2017.

Esses números indicam que o incremento no conveniamento priorizou as matrículas em creche, especialmente em período integral, enquanto nas instituições públicas o atendimento em período integral foi reduzido. Na pré-escola, observamos que, apesar de haver um aumento nas matrículas conveniadas, o incremento foi nas matrículas em período parcial nas instituições públicas. Desse modo, é possível afirmar que o conveniamento foi mais expressivo na creche e que na a pré-escola a estratégia expressiva foi a parcialização do atendimento.

Considerando o objetivo desse texto, é importante observar que outro fenômeno foi registrado no Município: a partir do ano 2017 o conveniamento também pôde ser realizado com instituições privadas com fins lucrativos. Dessa forma, ao observarmos os tipos de instituições que firmaram o convênio no ano de 2017 para o atendimento da Educação Infantil, trinta instituições se declararam privadas, nove instituições se autodenominaram filantrópicas e duas, comunitárias (uma das instituições se declarou filantrópica e comunitária). Logo, no cenário atual, segundo dados da pesquisa, 73\% são instituições privadas com fins lucrativos.

Esses números, específicos do conveniamento, quando desdobrados em número de vagas que essas instituições privadas possuem, indicam que muitas sobrevivem do processo de conveniamento. Em termos numéricos temos a seguinte situação: 
Quadro 5 - Número de matrículas, por período de atendimento instituições conveniadas 2017

Vaga Própria

Integral

Creche Pré-escola Creche Pré-escola

201

262

418

Total de Vagas Própria

872
Vaga Conveniada

Integral Parcial

Creche Pré-escola Creche Pré-escola

$1480 \quad 31 \quad 109$

1511

145

Total de Vagas Conveniada

1765

Fonte: Elaboração própria a partir dos dados dos questionários.

Os dados demonstram que do número total declarado de vagas disponíveis nos Centro de Educação Infantil (CEIs) conveniados, 1.765 vagas (66,93\%) são destinadas ao conveniamento, destas, $85,60 \%$ de vagas de tempo integral e $90,03 \%$ de vagas na creche. Destaca-se que sete instituições (17,5\%) não responderam essas perguntas, o que pode minimizar os resultados. Outro aspecto que é possível destacar é que boa parte das instituições pesquisadas apresentam grande percentual de vagas conveniadas. A análise dos dados permitiu apontar que $17,5 \%$ dos CEIs possuem $100 \%$ de vagas conveniadas, e outros $50 \%$ possuem entre $50 \%$ e $99 \%$ de vagas conveniadas. Somente $15 \%$ das instituições possuem menos que $50 \%$ das suas vagas destinadas ao conveniamento.

Verifica-se que as vagas conveniadas representam número significativo no atendimento das instituições pesquisadas, no entanto, essas instituições também indicam que são mantidas por recursos oriundos de outras fontes, como a mensalidade cobrada das famílias que não possuem vagas conveniadas. De acordo com Susin (2008, p.68), esse fato as insere entre a "propriedade estatal e a privada, conservando seu caráter público pelo atendimento a uma política social de relevante interesse para a sociedade".

Desta feita, entendemos que essa lógica de gestão segue o preconizado pela Terceira Via, a qual indica ser necessário fortalecer a sociedade civil por intermédio de suas políticas de delegação (LATHAM, 2007, p. 54). Seguindo essa premissa, isso não significa um governo menor, mas um governo diferente, onde o Estado é um facilitador, um habilitador, "ainda envolvido no custeio e na regulamentação dos serviços, mas não necessariamente em sua prestação" (LATHAM, 2007, p. 54).

Consoante essa racionalidade, a Terceira Via entende que, ao delegar para sociedade civil, há um modo de proporcionar capital social, sistemas "proativos" e bem-estar social, que 
permitam aos sujeitos prosperar na era global. Por isso, ao analisarmos como os CEIs pesquisados se apresentam em relação ao número de vagas conveniadas, encontramos um CEI com apenas 4 (quatro) vagas próprias (mantidas por outra fonte de recurso) e 60 (sessenta) vagas conveniadas, o que indica que a manutenção dessa instituição depende fortemente do convênio com o poder público. Essa situação é também observada em outras instituições, como o CEI 6 com 6 (seis) vagas próprias e 80 (oitenta) vagas conveniadas; CEI 14, com 5 (cinco) vagas próprias e 43 (quarenta e três) vagas conveniadas; CEI 26, com 4 (quatro) vagas próprias e 49 (quarenta e nove) vagas conveniadas e CEI 27, com 9 (nove) vagas próprias e 75 (setenta e cinco) vagas conveniadas.

Entretanto, se os dados parecem revelar que o conveniamento é algo proveitoso para a iniciativa privada, as análises não indicam essa perspectiva, pois 32,5\% das instituições conveniadas estão insatisfeitas com os critérios do conveniamento. Mesmo assim, quase a totalidade das instituições (90\%), possui interesse em renovar o convênio com a Secretaria de Educação Municipal. Dentre as reclamações mais recorrentes se encontra a discordância sobre o valor repassado pelo convênio, considerado baixo pelas instituições, além da morosidade para receber os recursos e o nível de exigência para atender os critérios de conveniamento. De modo especial, questionamos como é a qualidade desse atendimento, considerando que as instituições reclamam do valor insuficiente do conveniamento.

Essa observação das instituições se torna ainda mais preocupante se considerarmos, como indicam os dados, que o maior número de vagas conveniadas é na etapa creche, no período integral, que sempre apresenta custo mais elevado. Soma-se a esse o fato de que, ao delegar para a sociedade civil, afasta-se o Estado de seu dever, blindando-o inclusive das pressões sociais. Por meio de discursos e palavras como "cidadania", "empreendedorismo", "colaboração" e "responsabilidade social", tão intensamente repetida nos discursos oficiais, é definida a "nova sociedade civil" (CAMPOS, 2017).

\section{Considerações finais}

Os rearranjos entre o público e privado na Educação Infantil, com modificação do papel do Estado, que transfere a execução das políticas educacionais para a sociedade e assume as funções de agente fiscalizador ou, como denomina Dale (2014), "uma nova gestão pública", possuem efeitos deletérios na concretização do direito à educação na lógica de um projeto coletivo e emancipatório. 
Outro aspecto que merece atenção é como a "sociedade civil" passa a ser compreendida na perspectiva da Terceira Via, posto que, como podemos observar, os convênios são realizados, não a partir de um projeto comum e coletivo, mas como uma negociação e, nesse sentido, "a sociedade civil" resulta em uma realidade autônoma, convertendo-se em um espaço esvaziado na luta por direitos sociais. Em outras palavras, a sociedade civil "não é compreendida como cenário do embate político entre as classes, que levam a termo seus conflitos" (PERONI, OLIVEIRA e FERNANDES, 2012 p. 769). Antes, é compreendida como se não existissem antagonismos, confronto de classes e lutas contra hegemonias (PERONI, OLIVEIRA e FERNANDES, 2012).

\section{Referências}

ADRIÃO, Theresa Maria de Freitas; PERONI, Vera Maria Vidal. Consequências da atuação do Instituto Ayrton Senna para a gestão da educação pública: observações sobre 10 estudos de caso. Práxis Educativa, v. 6, p. 31-44, 2011. Disponível em:

http://www.revistas2.uepg.br/index.php/praxiseducativa/article/view/2522/1998. Acesso em 07/04/2018.

CAMPOS, Rosânia. Educação Infantil e organismos internacionais: uma análise dos projetos em curso na américa latina e suas repercussões no contexto nacional. Tese Programa Pósgraduação em Educação. UFSC: Florianópolis, 2008.

CAMPOS, Rosânia. As políticas de expansão da Educação Infantil a partir da Lei $\mathrm{N}^{\circ}$ 12.796/13: análise das propostas para crianças de 0 a 3 anos. Relatório de Estágio pósdoutoral. Universidade Federal do Rio Grande do Sul, 2015.

CAMPOS, Rosânia. As políticas de expansão da Educação Infantil a partir da Lei No 12.796/13: análise dos dez maiores Municípios do Estado de Santa Catarina. Relatório de Pesquisa. CNPQ, 2016.

CAMPOS, Rosânia e BARBOSA, Maria Carmen Silveira. A obrigatoriedade da matrícula na pré-escola em tempos de "terceira via". $38^{a}$ Reunião Nacional da ANPEd, São Luís do Maranhã, 2017.

BRASIL. Constituição da República Federativa do Brasil: promulgada em 5 de outubro de 1988. Brasília, DF: Senado federal/Centro gráfico, 1988.

BRASIL. Plano Diretor da Reforma do Aparelho do Estado, Brasília: Presidência da República, Câmara da Reforma do Estado, Ministério da Administração Federal e Reforma do Estado, 1995. Disponível em: http://www.biblioteca.presidencia.gov.br/publicacoesoficiais/catalogo/fhc/plano-diretor-da-reforma-do-aparelho-do-estado-1995.pdf.

Acesso em 13/06/2018. 
BRASIL. Lei $n .^{\circ} 9.394$, de 23 de dezembro de 1996. Estabelece as diretrizes e bases da educação nacional. Diário Oficial da União. Brasília, DF, 1996.

BRASIL. Lei $n^{\circ} 11.114$, de 16 de maio de 2005. Altera os arts. 6º 30,32 e 87 da Lei ${ }^{\circ} 9.394$, de 20 de dezembro de 1996, com o objetivo de tornar obrigatório o início do ensino fundamental aos seis anos de idade. Diário Oficial da União. Brasília, DF, 2005.

BRASIL. Lei $n^{o} 11.274$, de 6 de fevereiro de 2006. Altera a redação dos arts. 29, 30, 32 e 87 da Lei n ${ }^{\circ}$ 9.394, de 20 de dezembro de 1996, que estabelece as diretrizes e bases da educação nacional, dispondo sobre a duração de 9 (nove) anos para o ensino fundamental, com matrícula obrigatória a partir dos 6 (seis) anos de idade. Diário Oficial da União. Brasília, DF, 2006.

BRASIL. Lei $n^{o} 11.494$, de 20 de junho de 2007. Regulamenta o fundo de manutenção e Desenvolvimento da Educação básica e de valorização dos Profissionais da Educação FUNDEB, de que trata o art. 60 do Ato das Disposições Constitucionais Transitórias; altera a Lei ${ }^{\circ}$ 10.195, de 14 de fevereiro de 2001; revoga dispositivos das Leis $n^{\circ} \mathrm{s} 9.424$, de 24 de dezembro de 1996, 10.880, de 9 de junho de 2004, e 10.845, de 5 de março de 2004; e dá outras providências. Brasília, DF, 21 jun. de 2007a.

BRASIL. Lei $n^{\circ} 12.796$, de 4 de abril de 2013. Altera a Lei $\mathrm{n}^{\circ}$ 9.394, de 20 de dezembro de 1996, que estabelece as diretrizes e bases da educação nacional, para dispor sobre a formação dos profissionais da educação e dar outras providências. Diário Oficial da União. Brasília, DF, 2013.

DAKAR. Educação para todos: o compromisso de Dakar. Brasília: UNESCO, CONSED. Ação Educativa, 2001. Disponível em: http://unesdoc.unesco.org/images/0012/001275/127509porb.pdf. Acesso em: 02.05.2018.

DALE, Roger. Estado, globalização, Justiça social e Educação: Reflexões contemporâneas de Roger Dale. Entrevista concedida a Luís Armando Gandin. In currículo sem Fronteiras. V.14, n.2, p. 5 - 16, maio/ago, 2014.

FONTES, Virginia. A sociedade civil no Brasil contemporâneo: lutas sociais e luta teórica na década de 1980. In LIMA, Júlio César França e NEVES, Lúcia Maria Wanderley (orgs.). Fundamentos da educação escolar do Brasil contemporâneo. Rio de Janeiro: Editora FIOCRUZ, 2006.

GIDDENS, Anthony. A terceira via: reflexões sobre o impasse político atual e o futuro da social-democracia. Tradução: Maria Luiza X.de A.borges. $5^{\text {a }}$ edição. Rio de Janeiro: Record, 2005.

GIDDENS, Anthony (org.). O debate global sobre a terceira via. Trad. Roger Maioli dos Santos. São Paulo: Editora UNESPE, 2007.

KRAMER, Sônia. A política do pré-escolar no brasil: a arte do disfarce. $6^{\text {a }}$ ed. São Paulo: Cortez, 2001. 
KUHLMANN JR., Moysés. Infância e Educação Infantil: uma abordagem histórica. $7^{\mathrm{a}}$ ed. Porto Alegre: Mediação, 2015.

LATHAM, Mark. A terceira via: um esboço. In GIDDENS, Anthony (org.). O debate global sobre a terceira via. Trad. Roger Maioli dos Santos. São Paulo: Editora UNESPE, 2007.

PERONI, Vera M. V., OLIVERIA, Regina T.C de. E FERNANDES, Maria Dilnéia E. Estado e Terceiro setor: as novas regulações entre o público e o privado na gestão da educação básica brasileira. In Educ.Soc., Campinas, vol.30, n.108, p. 761 -778, out. 2009. Disponível em: www.ceded.unicamp.br.

PERONI, Vera Maria Vidal. Mudanças no Papel do Estado e Políticas Públicas de Educação: notas sobre a relação público/privado. In PERONI, Vera Maria Vidal e ROSSI, Alexandre José. Políticas educacionais em tempos de redefinições no papel do Estado. Porto Alegre: Programa de Pós-Graduação em Educação da UFRGS. Gráfica e Editora UFPEL, 2011.

ROSEMBERG, Fúlvia. Organizações multilaterais, estado e políticas de educação infantil, São Paulo, n. 115, março, 2002. Disponível em: http://www.scielo.br/pdf/cp/n115/a02n115.pdf. Acesso em 30/03/2018.

SUSIN, Maria Otilia Kroeff. O estatal e o público não estatal: onde está a educação infantil comunitária em Porto Alegre? In ADRIÃO, Theresa e PERONI, Vera (orgs.). Público e privado na educação: novos elementos para o debate. São Paulo: Xamã, 2008.

SUSIN, Maria Otilia Kroeff; MONTANO, Monique Robain. A educação infantil no Brasil: direito de toda criança ainda em construção. In PERONI, Vera Maria Vidal. Diálogos sobre as redefinições no papel do Estado e nas fronteiras entre o público e o privado na educação. São Leopondo: Oikos, 2015.

VIEIRA, Evaldo. A política e as bases do direito educacional. In Cadernos Cedes, ano XXI, no 55, novembro/2001 [p.09 -29]. Disponível em:

http://www.scielo.br/pdf/ccedes/v21n55/5538.pdf 